\title{
TRANSITION FROM CHARCOAL TO COKE IN IRON SMELTING IN BRITAIN
}

\begin{abstract}
$\mathrm{R}$
ATHER more than a year ago, the secretaries of the Royal Society of Arts discovered several bundles of old letters written to the Society between 1750 and 1800 . The find is rich in information relating to the then manifold activities of the Society and to the inventors of those days. The careful study of the letters by appropriate experts may be expected to throw much light on an all too little known aspect of history, that of technical progress.

Unfortunately, the disturbed state of the world mado it advisable to place the letters in safo leeping before the plans for their investigation could materialize. A beginning, however, had been made, and ono letter by J. Wilkinson, probably the same Wilkinson who produced cannon during the Napoleonic wars, formed tho raison d'être of a paper by Mr. H. Gwynn Jones on the charcoal iron industry, delivered before the Royal Society of Arts on November 15

Iron was at first smelted with charcoal by tho direct process, wherein furnace and forge were under one roof. As the amount of charcoal within economic range became exhausted, the indirect method camo into vogue in which pig iron was made in one locality and forged in another. The metal was run into $a$ bed of sand furrowed herring-bone fushion, and when cool broken into the 'sow' or central furrow and the 'pigs' or offshoots.

The evidence afforded by the location of the early iron works, which demanded a supply of wood for charcoal, of iron ore, water transport and swift-
\end{abstract}

flowing streams for power, gives an indication that the scarcity of charcoal was wide in its influence on the iron industry. The search for a substitute began before the eighteenth century; the first patent for coke was taken out in 1627 , and apparently the Darbys of Coalbrookdale had established colie smelting of iron on a commercial scale by 1709 , but it was thirty years or more later before a method of using coke in all the processes of smelting was discovered.

The long letter to the Society of Arts from Wilkinson written in 1761 makes it clear that at that date iron was produced mainly with charcoal. He suggests that the Society should consider how to make coke pig iron as good as that made with charcoal, next how to make tough bar iron from the coko pigs, and finally how to convert these into steel equal in goodness to that mado from Swedish bar iron. Ho writes : "this Kingdom has materials enough to mako all the iron that is consumed provided the coko schemo can be established in the making of pig iron equal in goodness to those mado with charcoal".

His remarks, besides showing that the iron industry was tied to charcoal in 1761, foreshadow the changes which were to take placo in the I3ritish iron industry when iron and coal wero finally wedded, causing it to lead tho world for at least a century.

As a result, the industry abandoned its scattered homes and becamo established in localities whero coal and iron were found side by side; a wooded district with rapid streams was no longer necessary.

\section{TORSIONAL EFFECTS OF TORSIONAL OVERSTRAIN IN MILD STEEL}

\begin{abstract}
A PAPEI by Prof. H. W. Swift on the torsional effects of torsional overstrain in mild steel, which had been prepared for presentation at the cancelled Cardiff Autumn Meeting of the Iron and Steel Institute, has been abridged and is published in Engineering of October 20. The usefulness of a material for manipulative processes in which severo plastic deformation is involved, depends primarily on the range of elastic flow to which it can safely be subjected. 'This depends in turn on, first, the stressstrain characteristics for the material within the elastic range; secondly, the stress-strain characteristics for tho material within the plastic rango; and thirdly the cohesive properties of the material which resist rupture.
\end{abstract}

The conditions of elastic breakdown have been the subject of much study and discussion. Some theories still havo their champions, but most engineers regard maximum stress as the criterion of brealkdown for brittle materials and shear-strain energy (or shearstress on the octahedral planes to which this is implicitly related) for ductile materials. In a ductile material it is generally thought that rupture occurs by shear. In a tensile stress the familiar cup and cone fracture indicates sliding at the instant of rupture, and in torsion the surface of rupture is a transverso plane of maximum shear stress. But it has been proved that the process of rupture at the neck of a ductile bar in tension always commences inside the material across what is substantially a plane of maximum tensile stress. Shear sliding on the cup and cone basis sometimes occurs to a measurable oxtent after fracturo has been initiated.

Simple tension and simple shear are the two simplest mothods of maling exploratory tests. In addition, measurements of hardness aro taken on the surface of tension of torsion bars at various stages of overstrain, and plotted in diagrams. Tables are shown of the principal test data relating to the tensile properties after torsional overstrain. It was found that after fracture had commenced (internally), which was proved by the sudden drop of the beam of the testing machine, a certain amount of drawing continued in the unbroken outer angular ring, ind the diameter at the neck after complete soparation was measurably less than that when the fracture commenced. It was found that neither strain energy nor hardness was a controlling factor in regard to rupturo. 